attempts to arrive at objectively verifiable statements of the kind required by QRA are forever doomed to failure. An opposite point of view is put in the third essay, but in a way that exhibits such abysmal ignorance as may be illustrated by the statement on $p 223$ : 'The first three holders of the chair of Eugenics (later statistics) at University College in London were Francis Galton, Karl Pearson, and R A Fisher. Their opposition to Mendelian theories of genetics (ie theories that postulated unobserved mechanisms responsible for inherited characteristics) and promotion of purely statistical approaches was notorious'. That Galton never held a Chair, and Fisher never held a Chair in statistics, are details readily found in the Dictionary of National Biography. However, to suggest that the man mainly responsible for reconciling Mendelism with Darwinism was a notorious opponent of the former would suggest that nothing the author says need be taken seriously. This is a pity, because his thinking, as opposed to his knowledge of facts, is a good deal clearer than that of his coauthors.

There has been an explosion of late in the literature connected with public risk assessment. The Royal Society Working Party report remains preeminent in its setting out of the issues to be faced. The essays in the first part of the present work make it a useful addition to the literature.

GEORGE A BARNARD Department of Mathematics, University of Essex

\section{Medicine Looks at the Humanities}

J David Neville, Ira W Gabrielson, 184 pages, London, $\$ 24.50 \mathrm{hbk}, \$ 12.75$ pbk, University Press of America, 1987.

This book is a celebration by the Medical College of Pennsylvania of a decade of collaboration between doctors, scientists, philosophers and teachers of the humanities. Their aim was to create a medical curriculum which included the humanities in the hope that a more mature, 'humane' physician could be created to practise in our scientific world. Humanities are defined as subjects such as poetry or philosophy which enhance our knowledge of human feelings and ways of communicating through words, art and music.

The book is divided into five parts: Perspectives, Interpretations, Expressions, Attitudes and Prescriptions.

Part One is a collection of essays by doctors assessing what qualities can be learned from the practice or appreciation of different humanities. The development of communication skills enables the practitioner to empathise with different people in different situations. In the context of medicine when a cure is not possible the writers feel that it is important that doctors care and try to alleviate suffering.

Part Two the Interpretations, consists of four critical appreciations of four works of literature and art. The Expressions in Part Three include poems, short stories and essays which harvest the experiences of students and doctors. They present insights into some of the emotional dilemmas we face in the practice of medicine. In Part Four the survey of attitudes to the humanities in a medical community is presented clearly in tables. The interpretative essay analyses the attitudes of nurses, medical students, administrators and doctors to the arts. The final section looks at ways medical education could be developed to include humanities in its curriculum.

There is no question of compromising the clinical knowledge and skills acquired by medical students, rather the humanities faculty wants to increase the maturity of the student's application of this scientific knowledge to individuals. There is awareness that the arts can complement the sciences in the analyses and resolution of problems in medical care: as we become increasingly 'high-tech' we should become 'high-touch' doctors.

The study of the humanities may help us to know ourselves and to know what it is to be human. This book succeeds in showing us the different qualities we can learn from the study of different humanities and how useful these skills can be to the growing doctor.

For me the energy of the book lies in Part Three, where young doctors express their ethical dilemmas in poems and short stories. There was a freshness in their reflections.

The disappointment is Part Two. The critical appreciations by medical minds are at times incomprehensible; the uncorrected type-script in the essay on the 'Border-line Personality' contributes to the confusion.

Overall I am grateful to realise that there are artists and writers out there in the medical profession, and that there are people who wish to nurture these skills in medical students and have already started doing so.

OENONE BROWN Principal in General Practice 100 Falcon Road, London SW11

\section{Medical Ethics and Economics in Health Care}

Edited by Gavin Mooney and Alistair McGuire, 159 pages, Oxford, $£ 20.00$, Oxford University Press, 1988.

At first sight the conflict between health economics and medical ethics is irreconcilable. Economists are essentially utilitarian, seeking the maximisation of social welfare. Resource allocation decisions in health care, however, are made largely by doctors whose code of medical ethics at least as perceived by economists directs them to maximise the welfare of the individual patient and to ignore opportunity cost (the benefit foregone by not using the resources elsewhere). Since social welfare is maximised when opportunity costs are minimised, medical ethics ensures social suboptimality.

Medical Ethics and Economics in Health Care is a collection of papers presented at a workshop which brought together a multidisciplinary group, including doctors and economists, to debate the nature, extent, and possible resolution of this conflict. The papers show that there is more involved than first meets the eye. Indeed several of the authors argue that the basic conflict as presented above is oversimplistic: utilitarianism is more than the sum of the (value of) health outcomes, and medical ethics does not, in theory or practice, wholly ignore opportunity cost. The extent to which each aspect oversimplifies, however, is debatable. Examples of doctors' concern with opportunity cost, such as Raanan Gillon's case of the general practitioner who terminates a productive session with a psychologically disturbed patient because another is suffering a myocardial infarction in the waiting room, show that doctors' ignoring of opportunity cost is clearly not absolute. But proof that some doctors consider opportunity cost some of the time does not alter the fact that most do not most of the time. 